\title{
Pneumatic Breakwaters and Their Use for Ships Protection in Coastal and Offshore Areas of the Persian Gulf
}

\author{
Milad Bamdadinejad a , Mohammad Javad Ketabdari ${ }^{\text {a }}$, Saman Rezaei ${ }^{\text {a }}$ \\ a) Department of Maritime Engineering, Amirkabir University of Technology, Tehran, Iran \\ *Corresponding author: ketabdar@aut.ac.ir
}

\section{Paper History}

Received: 29-August-2020

Received in revised form: 13-November-2020

Accepted: 30-November-2020

\begin{abstract}
Pneumatic breakwater is a kind of wave energy damping structure which is capable of reducing a portion of wave energy. The structure utilizes an air bubble column deep in water to induce a counter flow which opposes the wave current resulting in damping of its energy and the height of the wave. Fast installation with the least space occupied along with posing no obstacle for shipping and maneuvering are advantages of this structures. However, one of the disadvantages of this method is wasting almost half the energy of outgoing air. Using this method, a range of waves with lower height can be achieved. To draw the most advantage out of this method, the pneumatic breakwater can be combined with floating breakwaters. In order to explore the effectiveness of hybrid breakwater, a physical or numerical model in deeper water depth is required. Utilizing this method in coasts where other kind of ordinary breakwaters are not applicable and temporarily in the vicinity of shore in deeper water is economically effective. This breakwater can be attached to the ship (DAHET) or rig (ATAB). Hybrid system creates a safe atmosphere for smooth transfer of the passengers of crew boats to and from wharf in a continuous manner even in rough sea and bad weather condition. The results of this research for case study in Persian Gulf indicates that pneumatic breakwater is practical in Persian Gulf except for longitude between $51^{\circ}$ and $57^{\circ}$ and latitude between $24^{\circ}$ and $28^{\circ}$ Northern which extends from eastern north to 14 Kilom of Parsian Coasts and 30 Kilom of Lengeh Port and from western south to 6 Kilom of Dubai coasts to Abuzabi and from eastern north to $12 \mathrm{~km}$ of Kargan port to Sirik and from western south to 130 Kilom of eastern coasts of Qatar.
\end{abstract}

KEY WORDS: pneumatic breakwater, air bubble column, wave energy attenuation, hybrid breakwater.

$\begin{array}{ll}\text { NOMENCLATURE } \\ H_{t} & \text { Transmitted wave height } \\ H_{i} & \text { Incident wave height } \\ \omega & \text { Wave angular frequency } \\ g & \text { Gravity acceleration } \\ \mathrm{k} & \text { Wave number } \\ h & \text { Wave height } \\ m & \text { Beach slope } \\ W_{a} & \text { Wave attenuation }\end{array}$

\subsection{INTRODUCTION}

The coastal environment is one of the most important environmental systems that rapidly changes under the influence of hydrodynamic processes and perhaps, is not comparable with other geomorphologic systems [1,2]. Wave damping is one of the approaches to reduce the wave height. Pneumatic breakwater is a new generation of breakwaters which has effective functionality in ample conditions. In this breakwater compressed air is forced into a perforated pipe located under free surface in depth of water.

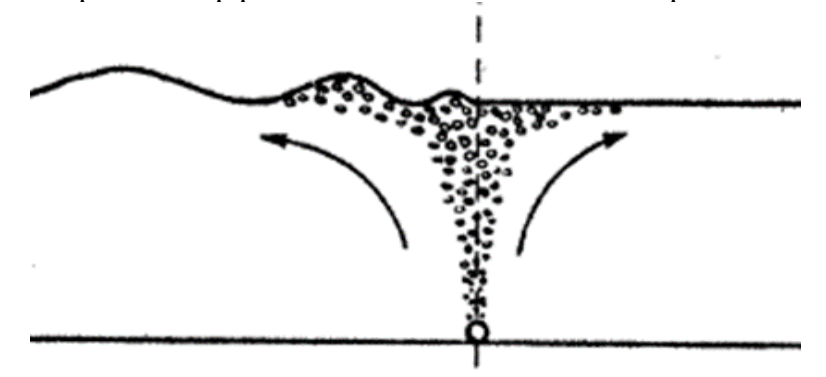

Figure 1: Pneumatic Breakwater Mechanism on wave height attenuation. 
The bubbles of air then pass through the holes in the pipe and come to the surface of water creating a counter current flow which opposes the incoming wave and consequently damps the wave energy (See Figure1)

Taylor (1955) initiated the first studies on pneumatic breakwater and demonstrated that when counter current flow is forced against the incoming waves, only the waves with shorter height are damped [3]. Iwagaki et al. (2013) explored the effect of combining pneumatic breakwater with other types of breakwater through series of experiment of hydraulic model [4]. In their experimental work pneumatic breakwater was combined with a Submerged breakwater and then with a floating breakwater. The results indicated that the wave transmission coefficient of combined breakwaters is less than that of each individual breakwater and that this combination is only economically effective when opposing short waves and for a short period of time. Liang (2006) scrutinized the history of pneumatic breakwater [5]. He mentioned that if the perforated air pipes are located in greater water depth, it will be more effective in damping of the waves. This method can be used in coastal area for establishing a safe atmosphere for marine vessels near the offshore terminals and safer berthing of oil tankers. Ghodsi Hassanabad et al. (2015) performed a numeric studied on the effectiveness of pneumatic breakwater through ANSYS Fluent Software [6]. In their experiment the optimized flow of the air in order to maximize the damping effect was estimated for different wave heights. They concluded that for a fixed wave height, with increasing the length of the wave, the rate of outgoing air bubbles should increase accordingly in order to reach the maximum damping. Evance (1955) showed that amortizing of tall waves with this method requires the consumption of more energy [7]. He established pneumatic breakwater with two methods. First by blowing the air directly and second by blowing it through small holes and thus creating air bubbles. The quality of the produced current in the second method was better than the first method by 10 percent. He used filters which had hundreds of microscopic holes for creating the air bubbles in his experiment. Reduction of waves height by air bubbles was shown in Figure 2 and the tools to create wave in laboratory was shown in Figure 3.

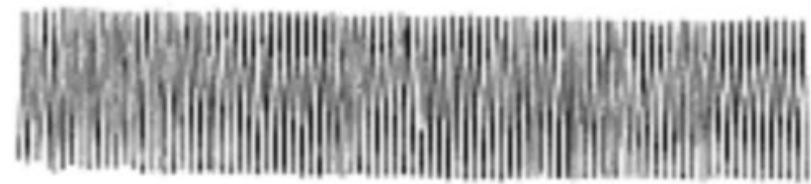

(a)

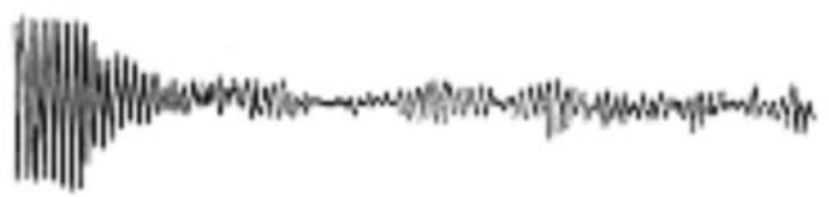

(b)

Figure 2: Reduction of wave height by air bubbles in laboratory: a) The wave formed in the laboratory with a height of $44.1 \mathrm{~m}$ at a depth of $0.09 \mathrm{~m}$ and b) Decreased wave height using air intakes [7].

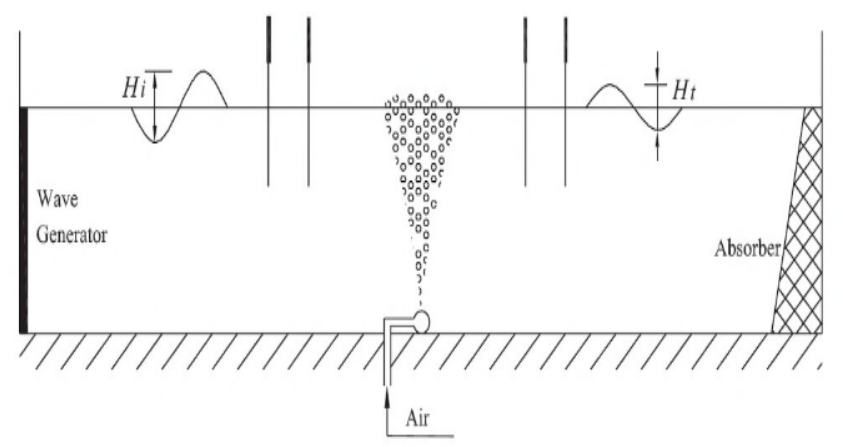

Figure 3: Laboratory equipment for testing pneumatic breakwaters [8].

In Figure 3, wave attenuation is estimated as:

$$
W_{a}=\frac{H_{t}}{H_{i}}
$$

where $\mathrm{W}_{\mathrm{a}}$ is wave attenuation and $\mathrm{H}_{\mathrm{i}}$ and $\mathrm{H}_{\mathrm{t}}$ are incident and transmitted wave heights, respectively.

The flow of air bubbles in the water column induces a wave which in turn opposes the incoming wave. When two waves reach the same point, the induced wave depreciates the energy of incoming wave if its height is greater than the incoming wave and consequently reduces the height of incoming wave. This phenomenon occurs efficiently only when the velocity of the current created by air bubble column is smaller than that of the incoming wave by 4 times (1/4 of the velocity of the incoming wave). However, damping of the wave energy will not be economically feasible if the incoming wave length is greater than $60 \mathrm{~m} \mathrm{[7]}$.

Koo (2009) simulated a pneumatic-type floating breakwater in the time-domain to evaluate wave blocking and wave energy absorption [9]. He et al. (2012) did an experimental study on the hydrodynamic performance of floating breakwaters with and without pneumatic chambers [10]. Paprota et al. (2017) did a theoretical approach to study interaction of linear water waves with an air bubble curtain used as a pneumatic breakwater [11].

In this paper first the history of pneumatic breakwaters followed by their advantages and disadvantages explains. Then the proper locations in Persian Gulf where this type of breakwater can be implemented to protect the marine structures and floating vessels are proposed.

\subsection{ADVANTAGES AND DISADVANTAGES OF PNEUMATIC BREAKWATER}

Some of the advantages of pneumatic breakwater include less space occupation, posing no obstacle for shipping and maneuvering, low initial cost and less adverse effect on the environment comparing to other kinds of breakwater. Pneumatic breakwater induces current in two directions. The purpose is to attenuate the incoming waves with the induced current which encounters the incoming wave. However, in this regard a part of the energy producing the current will be lost leading to an efficiency of $50 \%$ [8]. Therefore, in order to protect the coast and prevent wasting energy, the breakwater should be as close as 
possible to the protecting walls. Figure 4 shows the currents created on both sides of the bubble column [8].

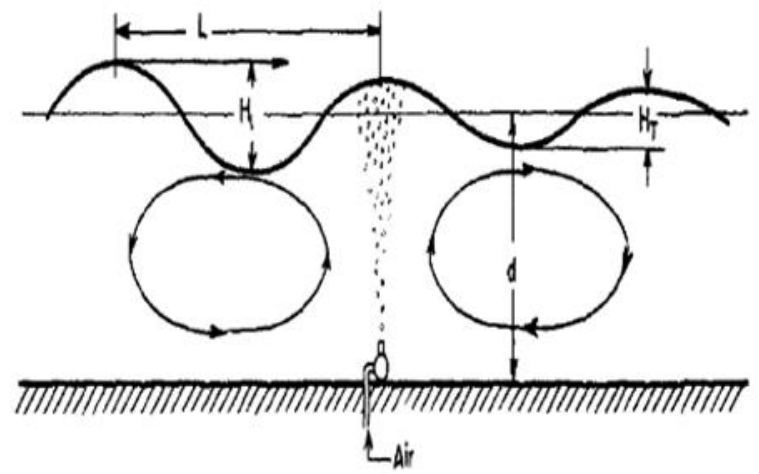

Figure 4: Mechanism of currents created around bubble column [8].

\subsection{APPLICATION OF HYBRID PNEUMATIC BREAKWATER}

Cruise and beaches entertainment are two major elements of marine tourism industry. Normally there is a lack of mooring equipment to restrain the cruisers in the tourist beaches. Big dimensions of these cruisers, depth limitation in these coasts, time-consuming berthing and its associated costs are the main reasons. Therefore, cruisers normally berth farther away from wharf and disembarkation of passengers is done through tender boat of the cruisers. Currently it is tried to perform transferring in calm sea condition. When cruiser ship anchors in harbor it can resist wind and wave leading to small movements in range. However tender boat will have turbulence against wavy sea so that even ladder cannot be maintained for safe embarking and disembarking of passengers.

To solve this problem, Beynet (2011) proposed a new concept of pneumatic breakwater called DAHET [12] (See Figure 5). In this method pneumatic breakwater is attached to the ship. When sea is choppy this breakwater comes out of ship hull and locates itself under the surface of water inducing air bubble column which in turn creates a calm area for the boats around the ship (See Figure 6). In this case there will be less clash between ship and boat resulting in safer transfer of passengers to and from the ship.

This method is applied only when sea is rough and passengers need to be embarked or disembarked. Therefore, only in such situation it is economically reasonable.

Other hybrid systems to protect wharf and quay is called ATAB which also uses pneumatic breakwaters (See Figure 7). This system comprises columns for creating air bubbles which is attached to the wharf's legs where boats and ships berth and protect it from waves.

By using two systems including ATAB and DAHET the whole services relating to passengers transferring from cruiser to tourist coasts is done safely. Quay for tender boats can be built outside of harbor with spending less time and money through ATAB method even when there is no space in harbor for boat to berth. Through combining two systems, safe transferring of passengers can be continued without the need for building new wharf or quay (Figure 8). Therefore, capacity of tourist coasts will increase by applying the combination of two methods.
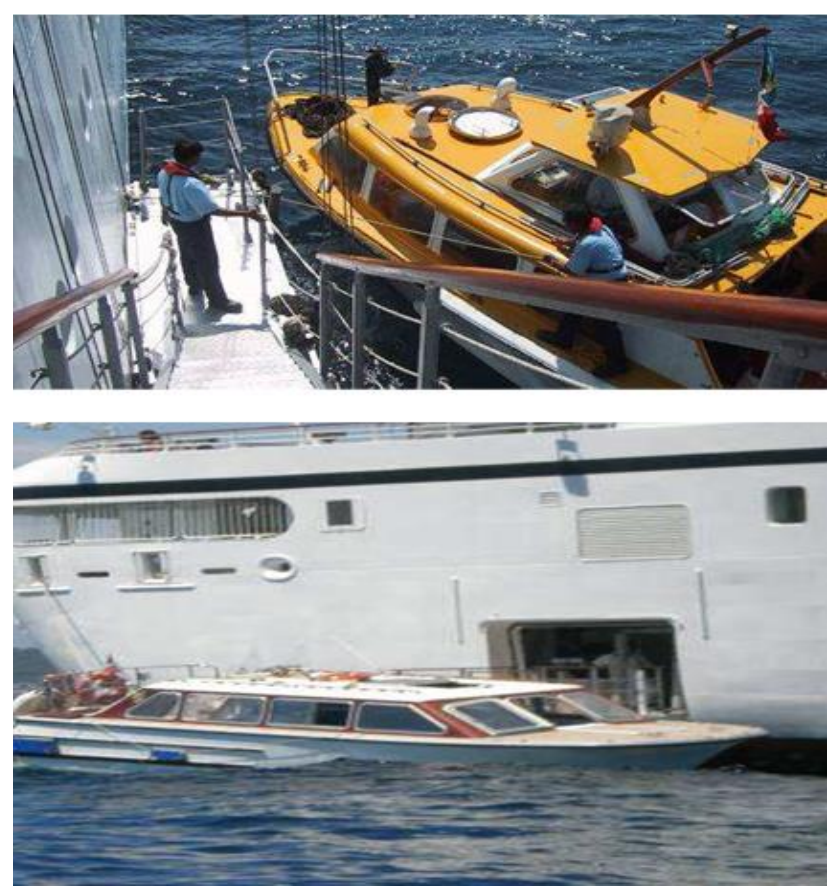

Figure 5: Tender boat hovering beside cruise ship in the conditions of the calm and rough seas [12].

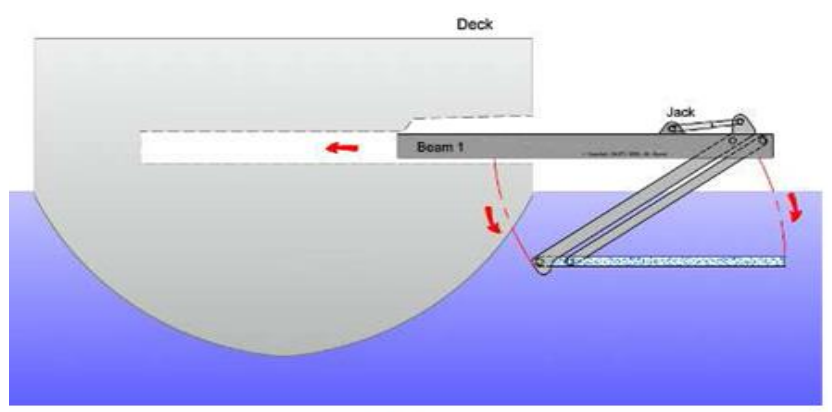

(a)

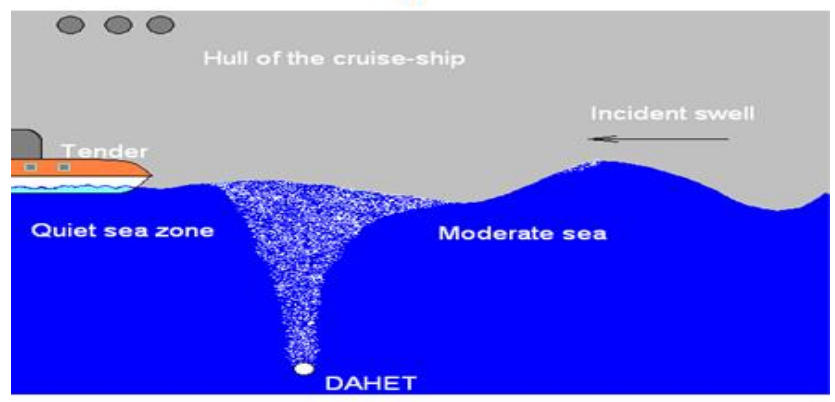

(b)

Figure 6: The DAHET hybrid system a) The DAHET hybrid system is being opened and b) The outflow of the wave bubble within the range of the boat mooring tender [12]. 

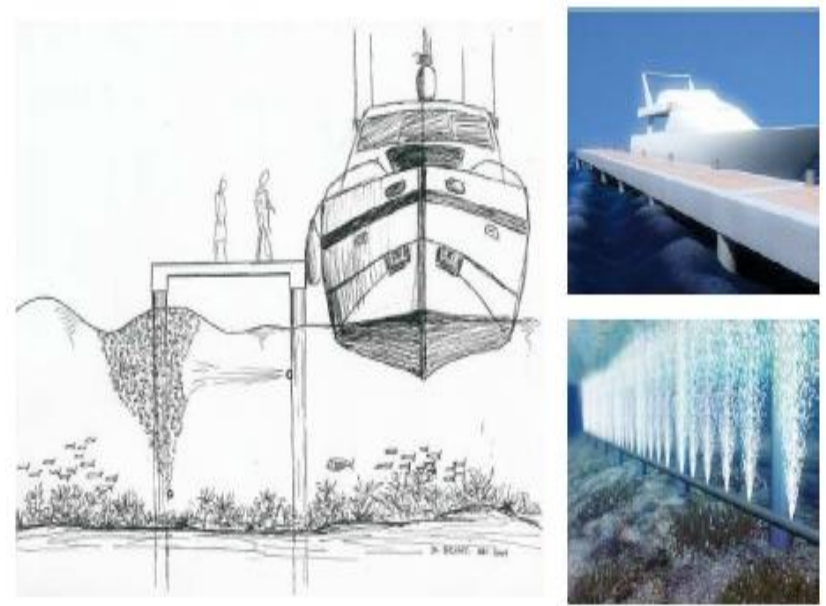

Figure 7: ATAB system for pleasure boat mooring and Tender outside the harbor [12].

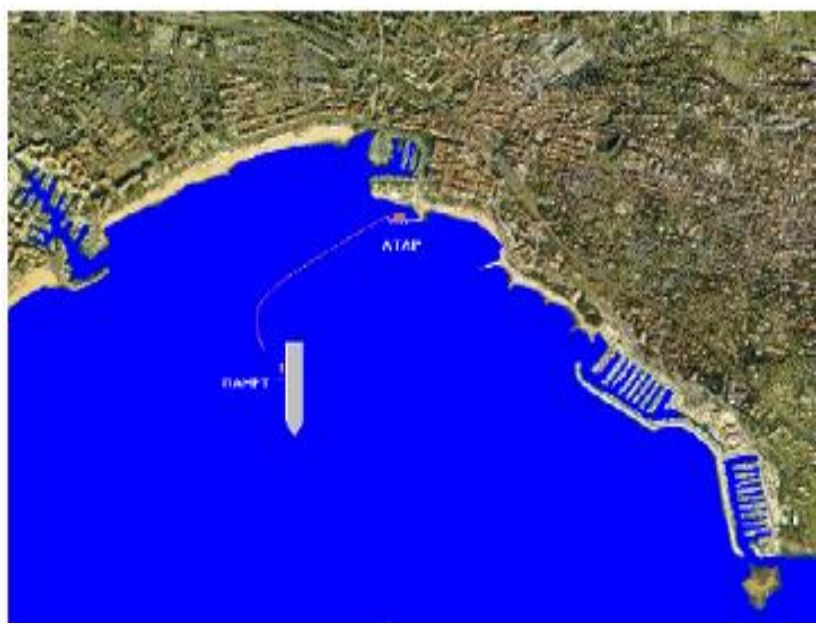

Figure 8: Continued safe transportation of passengers between the cruise ship and the tourist site by combining two ATAB and DAHET systems [12].

\subsection{FEASIBILITY STUDY ON PNEUMATIC BREAKWATER APPLICATION IN PERSIAN GULF COASTS}

Hydrographic maps and wave pattern period for the most areas of Persian Gulf (Figures 9 and 10) have been collected and studied. In this case study $15 \mathrm{~m}$ and $100 \mathrm{~m}$ depths for coastal and offshore areas have been considered respectively. With regard to the fact that pneumatic breakwater is not practical for the wave with more than $60 \mathrm{~m}$ wave length, period for this wave length is calculated through Dispersion equation as follows [13]:

$$
\omega^{2}=\operatorname{gktanh}(\mathrm{kh})
$$

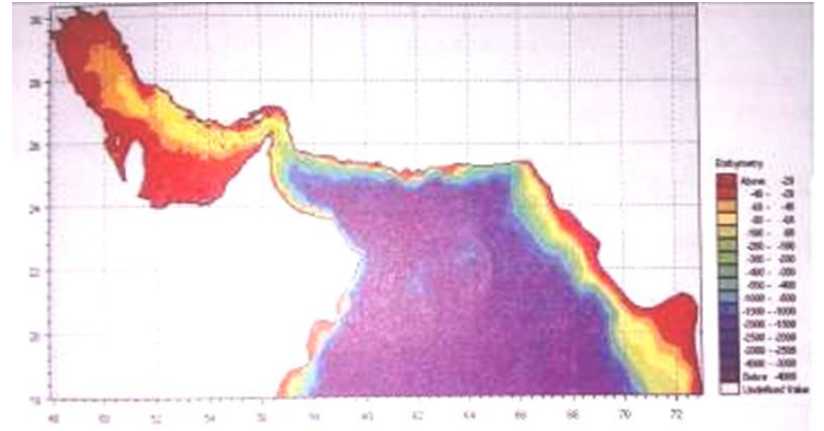

Figure 9: Hydrography of the Persian Gulf and Oman Sea (from a depth of $20 \mathrm{~m}$ with a red color to $4000 \mathrm{~m}$ with a dark purple Color) [14].

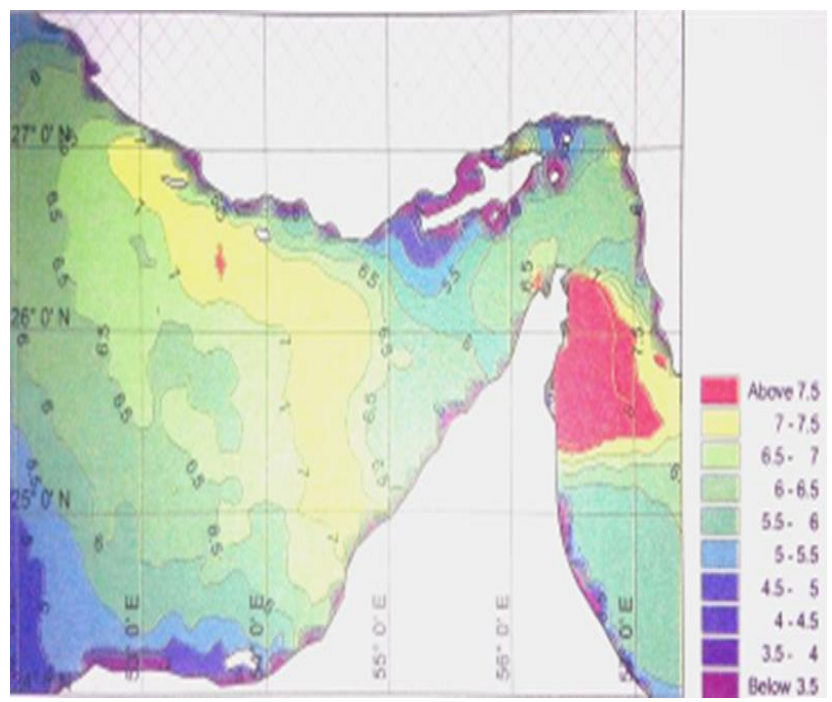

Figure 10: Wave period contours in the Persian Gulf [14].

Corresponding wave period for wave length range of less than $60 \mathrm{~m}$ is 6 seconds which is presented in Table 1 . Therefore, the area in Persian Gulf that has the least period can be utilized for installation of pneumatic breakwater.

Table 1: The wave period corresponding to wavelengths of $60 \mathrm{~m}$ in the coastal and offshore zones of the Persian Gulf obtained from Eq. (1).

\begin{tabular}{ccccc}
\hline Number & Type of case study & $\begin{array}{c}\text { Wavelength } \\
(\mathrm{m})\end{array}$ & $\begin{array}{c}\text { Depth } \\
(\mathrm{m})\end{array}$ & $\begin{array}{c}\text { Period } \\
(\mathrm{sec})\end{array}$ \\
\hline 1 & Onshore & 60 & 15 & 6.5 \\
\hline 2 & Offshore & 60 & 100 & 6 \\
\hline
\end{tabular}

Wave period of all regions in Persian Gulf is less than the area indicated with dim yellow having 6 seconds period [15]. In this area waves with more than $60 \mathrm{~m}$ in length are created and is not suitable for installing pneumatic breakwater (Figure 11). 


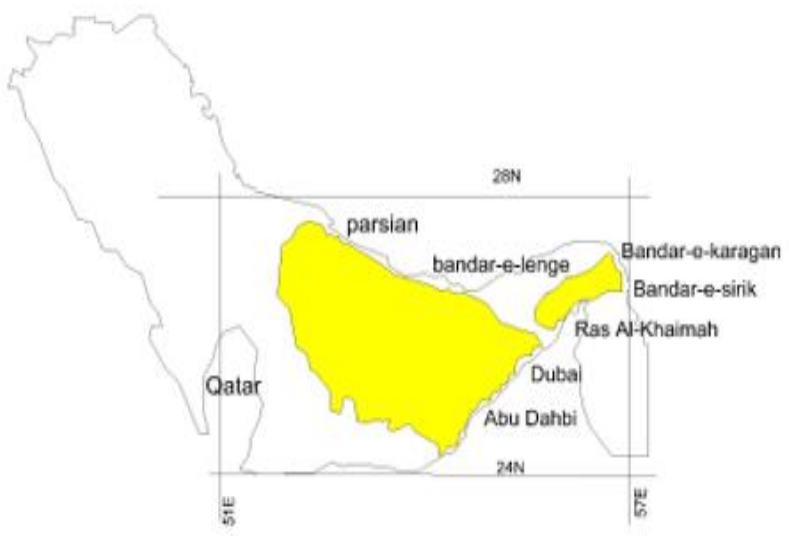

Figure 11: Inappropriate range for application of pneumatic breakwaters corresponding to wave period greater than $6 \mathrm{sec}$.

The earliest breaker criterion was that of McCowan (1894), who mentioned that waves break when their height becomes equal to a fraction of the water depth as follows [16]:

$$
\mathrm{H}_{\mathrm{b}}=\kappa \mathrm{h}_{\mathrm{b}}
$$

where $\kappa=0.78$ and the subscript $b$ denotes the value at breaking.

Weggel (1972) reinterpreted many laboratory results, showing a dependency of breaker height on beach slope $(\mathrm{m})$ as follows [17]:

Where:

$$
\kappa=b(m)-a(m) \frac{\mathrm{H}_{\mathrm{b}}}{\mathrm{gT}^{2}}
$$

$$
\begin{aligned}
& \mathrm{a}(\mathrm{m})=43.8\left(1-\mathrm{e}^{-19 \mathrm{~m}}\right) \\
& \mathrm{b}(\mathrm{m})=1.56\left(1+\mathrm{e}^{-19.5 \mathrm{~m}}\right)^{-1}
\end{aligned}
$$

which approaches $\kappa=0.78$ as the beach slope approaches zero.

Therefore, in this study Persian Gulf wave period was investigated for corresponding range of $60 \mathrm{~m}$ wave lenghth. The results show that this area is surrounded between longitudes $51^{\circ}$ and $57^{\circ}$ and latitudes $24^{\circ}$ and $28^{\circ}$ northern which extends from eastern north to 14 Kilom of Parsian Coasts and 30 Kilom of Lengeh Port and from western south to 6 Kilom of Dubai coasts to Abuzabi and from eastern north to 12 Kilom of Kargan port to Sirik and from western south to 130 Kilom of eastern coasts of Qatar. This information can be used as a framework for application of Pneumatic Breakwaters in this strategic area.

\subsection{CONCLUSION}

Pneumatic breakwater is a new type of breakwater which amortizes wave's energy through injecting air into air bubble column. This breakwater is economically practical for waves with less than $60 \mathrm{~m}$ length. To apply the breakwater for waves with higher range, the outgoing flow rate of air bubbles and depth of underwater pipes should be increased which naturally raises higher costs to protect coastal walls and in order to optimize the consumed energy, pneumatic breakwater should be installed as close as to the coastal walls. Pneumatic breakwater cannot be used as a permanent breakwater. This method is mostly applied in regions where use of breakwater is temporary or where ordinary breakwaters are not economically feasible. Fast installation with the least space occupied, posing no obstacle for shipping and maneuvering, low initial cost and less adverse effects on the marine environment are some of the advantages of this structures. Since the maintenance costs of this breakwater are high, this method is economically practical in cases such as in combination with floating breakwater, attached to ship and applying when transferring the passengers from ship to boats, applying in wharf where tender boats berth. Case study in Persian Gulf indicates that pneumatic breakwater can be built in all regions of Persian Gulf except for longitude between $51^{\circ}$ and $57^{\circ}$ and latitude between $24^{\circ}$ and $28^{\circ}$ Northern which extends from eastern north to 14 Kilom of Parsian Coasts and 30 Kilom of Lengeh Port and from western south to 6 Kilom of Dubai coasts to Abuzabi and from eastern north to 12 Kilom of Kargan port to Sirik and from western south to 130 Kilom of eastern coasts of Qatar.

\section{REFERENCE}

[1]. Yamani, M. and Nohegar, A., 2006. Coastal area location and literature review, In The Geomorphology of East Coast of Hormoz Strait, 1st Edn., 7-83, University of Hormozgan Publications, Bandar-e-Abbas, Iran.

[2]. Bamdadi Nejad, M., Ketabdari, M.and Shojaei, F., 2020. Numerical Modeling of Sediment Transport Rate and Shoreline Changes of Jazireh-e Shomali-Jonoubi Port in the Persian Gulf. Journal of Ocean, Mechanical and Aerospace -Science and Engineering-, 64(2), 39-45.

[3]. Taylor, G.I., 1955. The action of a surface current used as a breakwater. Proceedings of the Royal Society of London Series A. Mathematical and Physical Sciences, 231(1187), 466-478.

[4]. Iwagaki, Y., Asano, T. and Honda, T., 1978. Combination effect of pneumatic breakwater and other type breakwater on wave damping. In Coastal Engineering, 2172- 2190.

[5]. Liang, N.K., 2006. A reflection of pneumatic breakwater. Journal of Coastal and Ocean Engineering, 6(1), 85-99.

[6]. Ghodsi Hassanabad, M., Shegeft, M. and Ezam, M., 2015. Numerical modeling of pneumatic breakwater and its impact of wave damping, $17^{\text {th }}$ Marine Industries conference, Kish, Iran.

[7]. Evans, J.T., 1955. Pneumatic and similar breakwaters. Proceedings of the Royal Society of London. Series A. Mathematical and Physical Sciences, 231(1187), 457-466.

[8]. Straub, L. G., Herbich, J. B., and Bowers, C. E. 1957. An experimental study of hydraulic breakwaters. Coastal Engineering Proceedings, 1(6), 43.

[9]. Koo, W., 2009. Nonlinear time-domain analysis of motionrestrained pneumatic floating breakwater. Ocean Engineering, 36(9-10), 723-731.

[10]. He, F., Huang, Z. and Law, A.W.K., 2012. Hydrodynamic performance of a rectangular floating breakwater with and 
without pneumatic chambers: An experimental study. Ocean Engineering, 51, 16-27.

[11]. Paprota, M. and Sulisz, W., 2017. Modelling of wave transmission through a pneumatic breakwater. Journal of Hydrodynamics, Ser. B, 29(2), 283-292.

[12]. Beynet, J. M., 2011. Securing passenger transfer between cruise-ship and tender. Proceedings 7th Global Mast Maritime Systems and Technology, Parc chanot, Marseille, France.

[13]. Ketabdari, M.J. and Nazari Shahrbijari, A., 2006. Comprehensive computer model for analyzing raw data from waveguide buoys. $8^{\text {th }}$ Marine Industries conference, Kish, Iran.

[14]. http://www.pmo.com.

[15]. Faiz, J. and Ebrahimi-salari, M., 2011, November. Wave power resource in iran for electrical power generation. In Proceedings of World Renewable Energy Congress (34123419).

[16]. MCCowan, J., 1894. On the Highest Wave of Permanent Type. Philos. Mag. J. Sci., Vol. 38.

[17]. Weggel, J. R., Nov. 1972. Maximum Breaker Height. J. Waterways, Harbors Coastal Eng. Div., ASCE, 98(4). 